\title{
THE DAAS TREATMENT OF CHRONIC HCV INFECTION AND THE LIVER FIBROSIS EVOLUTION DURING TREATMENT: OUR EXPERIENCE
}

\author{
Andreea Rădășan², Mihai Voiculescu, ${ }^{1,2}$, Laura Elena Iliescu ${ }^{1,2}$ \\ ${ }^{1}$,, Carol Davila“ University of Medicine and Pharmacy, Bucharest, Romania \\ ${ }^{2}$ Internal Medicine Department, Fundeni Clinical Institute, Bucharest, Romania
}

\begin{abstract}
Introduction. Hepatitis $C$ is a liver inflammation caused by hepatitis $C$ virus. HCV is about 10 times as infectious as HIV. The acute infection rarely causes symptoms and can clear up spontaneously in the first six months in about $20 \%$ of those affected. In most cases, however, the infection becomes chronic (up to $80 \%$ ) 6 . Chronic hepatitis $C$ is a major cause of liver cirrhosis and hepatocellular carcinoma worldwide7. In the past decades, the standard treatment for hepatitis $\mathrm{C}$ viral infection was PEG-IFN and ribavirin (RBV). The future for the treatment of chronic hepatitis $C$ infection is represented by DAAs and for Romania, the future is called Exviera+Viekirax.

Objective of the study: The main purpose of the survaillance was to determine how these HCV chronic infection patients with F4 liver fibrosis tolerate the new DAAs treatment and how the liver fibrosis will decrease or increase.

Matherial and methods: The study enrolled 33 patients from Internal Medicine Center, Fundeni Clinical Institute, during the time period $02.2016-08.2016$. We evaluated the inflammatory syndrome, the cholestatic syndrome and the evolution of liver fibrosis.

Results: We have noticed a significant decrease of inflammatory syndrome, the bilirubin level decreased also, but the stage of liver fibrosis remained the same, at the end of treatment with Eviera+Viekirax.

Conclusions: We had a small experience so far, with Exviera+Viekirax regimen. The patients tolerated very well the therapy and the virological response was $100 \%$ for all subjects.
\end{abstract}

Keywords: hepatitis, HCV infection, therapy, liver fibrosis, evolution

\section{INTRODUCTION}

In 2016 we can say that we are witnesses at history, a medical history. By the end of 2015, in Romania, the most awaited oral therapy for hepatitis $\mathrm{C}$ virus is finally available. Our patients with HCV chronic infection receive from Romanian House of Health Insurances, the Viekirax + Exviera regimen. After years and years, when the only available therapy was the bi-therapy with Peg-Interferon and Ribavirin (RBV), which has it's very well-known side effects, we had a hope called „Boceprevir“ or „Telaprevir“, but both of them transformed into another disappointment. In 2014, the patients heard about „the new treatment". After this, it followed two years of mystery, tragedy, despair and in the end, triumph. In just a few words, this is what our patients felt in this period of time and we, doctors, also. The medical team from Internal Medicine Center of the Fundeni Clinical Institute was very involved because doctors knew patients for many years, and some of them have been diagnosed with chronic hepatitis $\mathrm{C}$ in this clinic.

HCV chronic infection is the leading cause of liver transplantation globally and in the entire 
world are infected between 130 and 170 million people (1-3). In Romania, the prevalence is about $5.6 \%$, without major statistical differences between men and women and the highest incidence is in 35-44 years old and 45-54 years old intervals. The consequences of HCV infection are liver cirrhosis, hepatocellular carcinoma (HCV chronic infection being the second most common cause of liver cancer) and finally, death.

In the past decades, the standard treatment for hepatitis C viral infection was PEG-IFN and ribavirin (RBV). The rate of SVR with this treatment in genotype 1 - patients, is at best $50 \%$ of patients. Another disadvantage of this therapy are the side effects, like fever, malaise, tachycardia, chills, headache, arthralgias, myalgias, anemia and so on (1).

The triple therapy consisting in directly acting antiviral agents (DAAs), telaprevir and boceprevir, both used in combination with PEGIFN and RBV therapy, improved enormously the SVR up to $75 \%$ of patients infected with HCV virus, genotype 1 . By the time the SVR raised, the tolerability was going down, due to the specific side effects of DAAs: rash, anemia etc (1).

The present and the future of HCV treatment are the new generations of DAAs generally, Exviera+Viekirax specifically for Romania.

\section{PURPOSE}

The aim of this study is to evaluate how all these pacients, treated with antiviral interferon free regimen tolerated this therapy and how their liver fibrosis decreases or increases during treatment.

HCV chronic hepatitis is the second common cause of liver cancer and affects between 130170 million people worldwide $(2,3)$. Most of the patients with chronic HCV infection develop a severe liver fibrosis and hepatic cirrhosis with it's complications. The most common HCV genotype is genotype 1 and the subtype $1 \mathrm{~b}$ is the most frequent in Romania. With the standard bi-therapy, PEG-IFN and RBV, the SVR was only $40-50 \%$ in naïve patients and for the other ones, with relapse or no viral response, the chance to cure was practically null.

The second generation of DAAs was a huge step in the attempt to eradicate the HCV infection. Unfortunately, in Romania, the patients who received the new treatment until now, were only the patients with stage 4 liver fibrosis. In this situation, our main question was how these patients will tolerate the therapy and what will happen with their liver fibrosis.

\section{MATHERALS AND METHODS}

We evaluated 33 patients with HCV chronic hepatitis who were in the evidence of Internal Medicine Center, Fundeni Clinical Institute for several years. All of them received the Exviera+Viekirax plus Ribavirin regimen during the time period $02.2016-08.2016$. This is an observational study, we observe and analyzed all the clinical changes and all the medical documents of the patients, with their entire permission. We observed their clinical status and we analyzed the evolution of transaminases, seric bilirubin, hemoleucograme, ARN level and liver fibrosis stage.

The statistical analysis was made with Microsoft Excel and the measurments of liver fibrosis were made with a FibroScan 502, Echosens, Paris. Only valid FibroScan measurments (according to the manufacturer's reccomendations) were included in the statistical analysis.

\section{RESULTS}

Patients included in this batch were men and women aged between 41 and 86, with aproximately equal distribution by sex, as it can be seen in the diagrames below (Fig. 1)

The most numerous patients are in the sixth decade (60-69 years) because this is the interval of age in which the HCV patients generally 


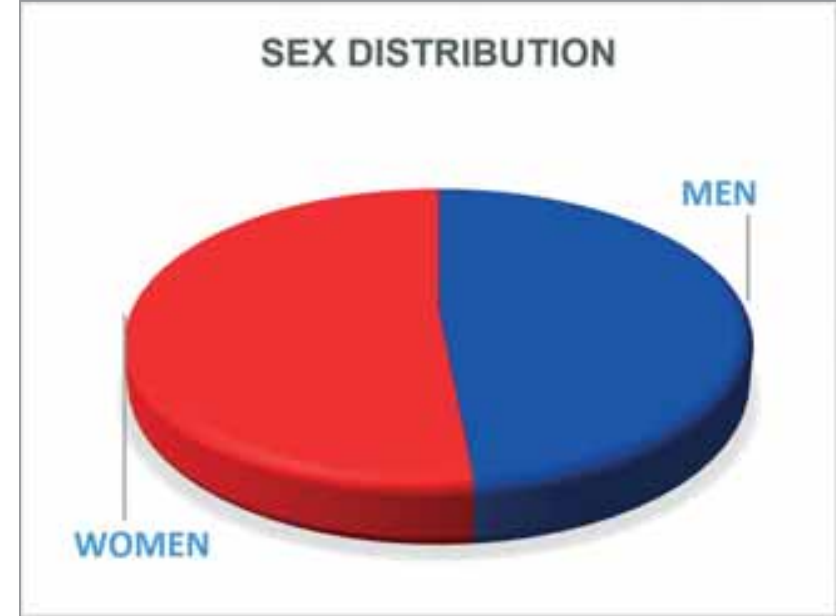

Figure 1. Sex distribution

develop stage four liver cirrhosis. Fibrosis progression leading to cirrhosis is estimated to occur in up to $20 \%$ of patients by 20 years of infection. However, the pace of progression to advance fibrosis/cirrhosis is highly variable between individuals and ranges less from 10 years to several decades $(4,5)$ (Fig. 2 ).

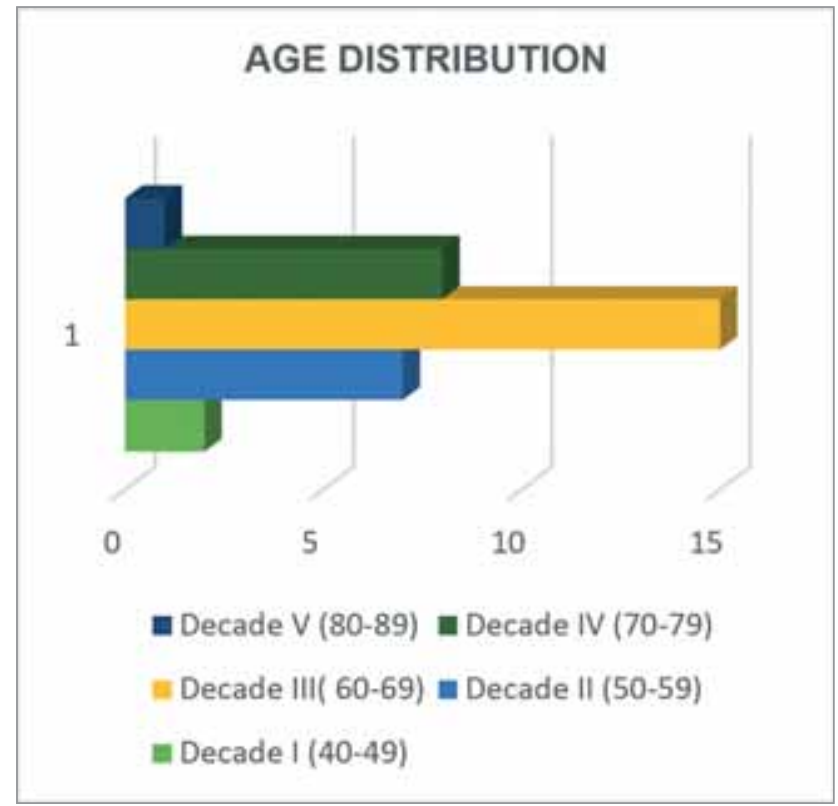

Figure 2. Age distribution

Concerning the therapeutic status of $\mathrm{HCV}$ chronic infection patients at the beginning of treatment, we included three groups of patients: first one was the group with naïve patients (patients who haven't received Peg-IFN/RBV therapy) $-12.12 \%$ ( 4 patients), the second group was the one with non-responder patients (patients without non-detectable viremia at the end of
Peg-IFN/RBV standard therapy) - 51.51\% (17 patients) and the last group was with relapse patients (patients with non-detectable viremia at the end of treatment, but who relapse after 6 months) - 36.36\% (12 patients) (Fig. 3).

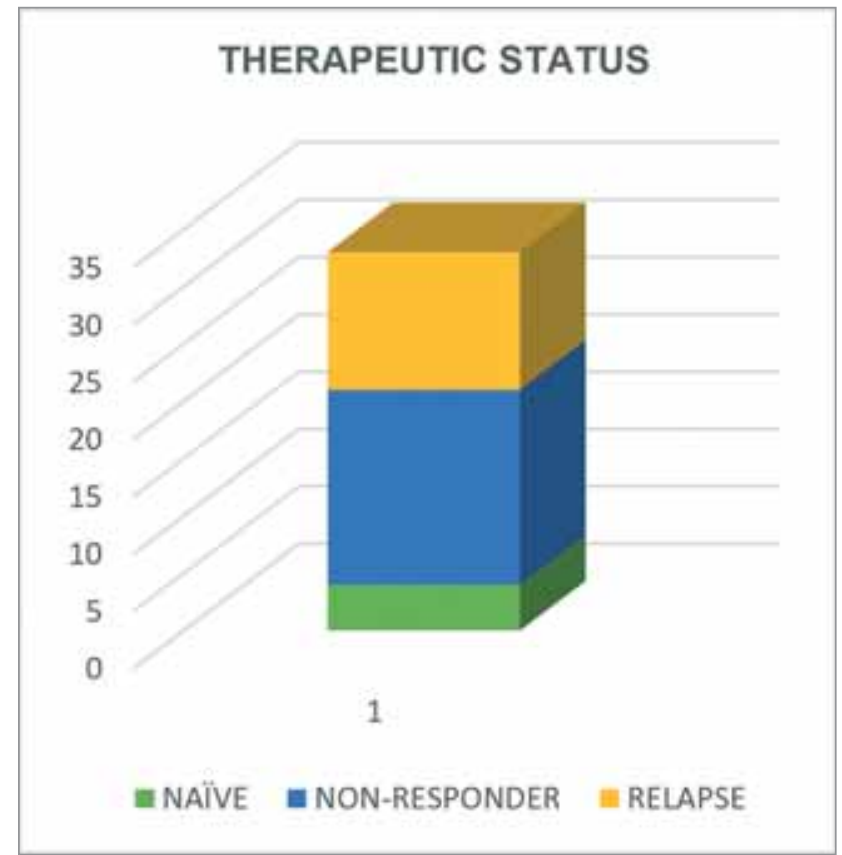

Figure 3. Therapeutic status of patients at the beginning of treatment

\section{CO-MORBIDITIES}
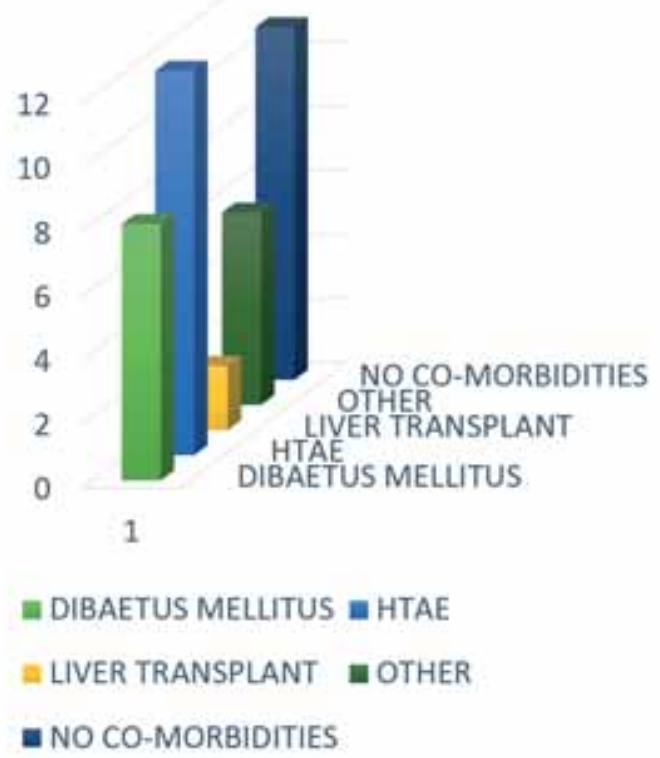

Figure 4. Co-morbidities of patients

Most of these patients had co-morbidities as it can be seen in the diagram above. From the total 
number of 33 patients, $36.36 \%$ (12 patients) has arterial hypertension, $24.24 \%$ (8 patients) had Diabetes Mellitus, 6.06\% (2 patients) had liver transplant for HCV liver cirrhosis, $18.18 \%$ (6 patients) had other co-morbidities like dyslipidemia, renal lithiasis, Biliary Lithiasis etc. and 33.33\% (11 patients) had no co-morbidities (Fig. 4).

The inflammatory syndrome, with ALT values more than 2 times normal values, was present in almost all patients. Just 6 patients $(18.18 \%)$ had

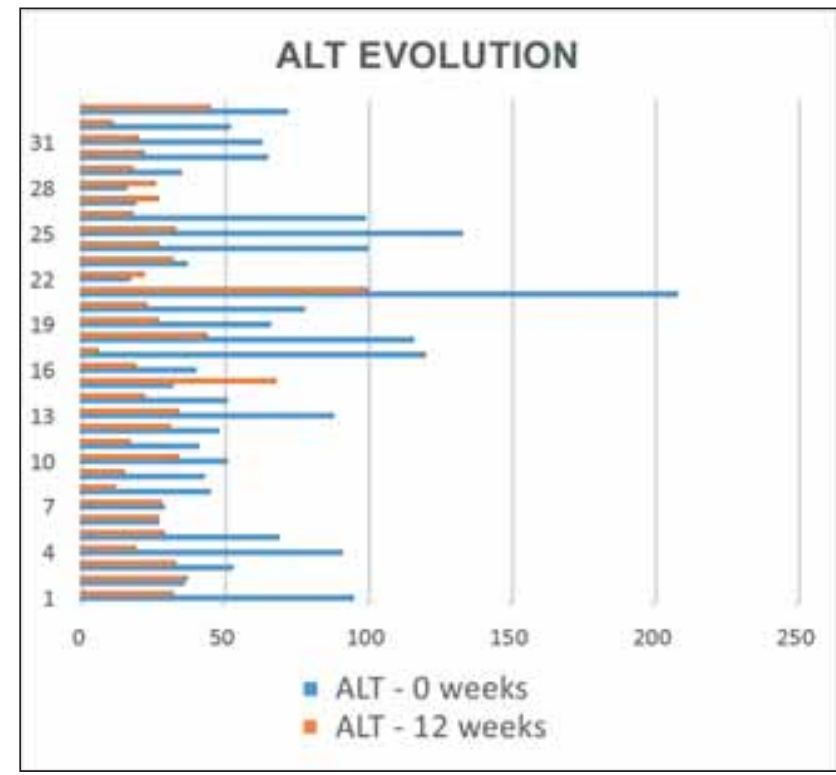

Figure 5. The ALT evolution

\section{EVOLUTION OF TOTAL BILIRUBIN}

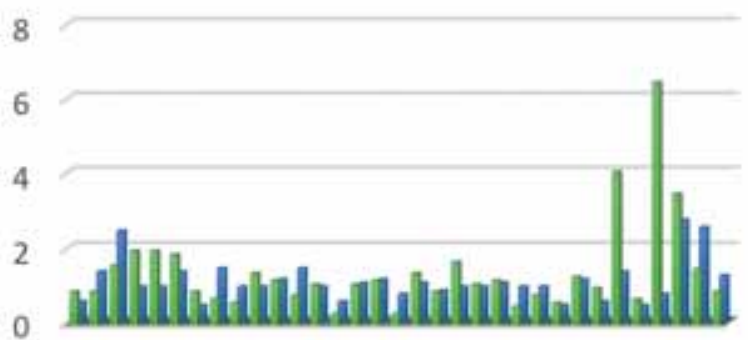

13579111315171921232527293133

atal Bilirubin 0 weeks $\mathbf{a}$ Total Bilirubin 12 weeks

Figure 6. Evolution of Total Bilirubin normal ALT values at the beginning of therapy. At the end of DAAs treatment the ALT level decreases in all patient and become normal in 29 patients (87.87\%) (Fig. 5).

The total bilirubin was with normal values in $57.57 \%$ (19 patients) at the beginning of therapy. At the end of treatment the values of total bilirubin became normal in $72.72 \%$ (24 patients) and only 3 patients (9.09\%) had an increase of bilirubin values, but with no more than $1 \mathrm{mg} / \mathrm{dl}$ (Fig. 6).

All the patients included in this study had FibroMax determinations with F4 liver fibrosis stage as a result, with only two exceptions - the two patients with liver transplant who had F0 liver fibrosis.

After transcutan elastography (FibroScan), one patient could not be explored with FibroScan because of the obesity, $66.66 \%$ (22 patients) had F4 liver fibrosis and $24.24 \%$ (8 patients) had F2F3 liver fibrosis at the beginning of treatment.

At the end of treatment, the liver fibrosis was the same in all patients, with a decrease with no more than $5 \mathrm{Kpa}$, but in the same interval of liver fibrosis stage (Fig. 7).

\section{FIBROSCAN EVOLUTION}

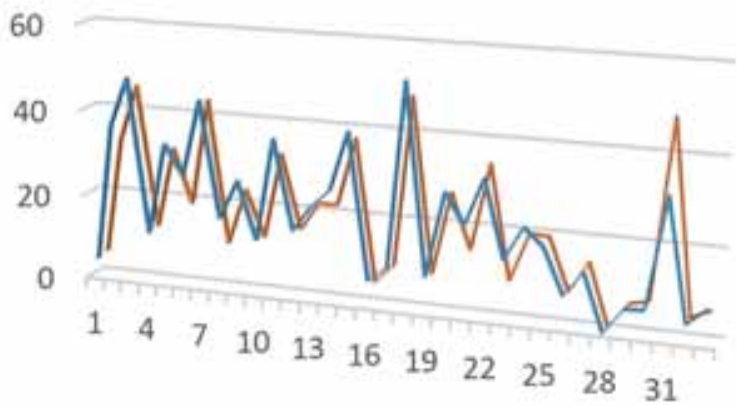

EibroScan 0 months $\mathbf{E}$ Fibroscan at 12 weeks

Figure 7. The FibroScan scores

Concerning the inflammatory syndrome, the subjects who had higher ALT levels had also higher FibroScan scores (Fig. 8). 


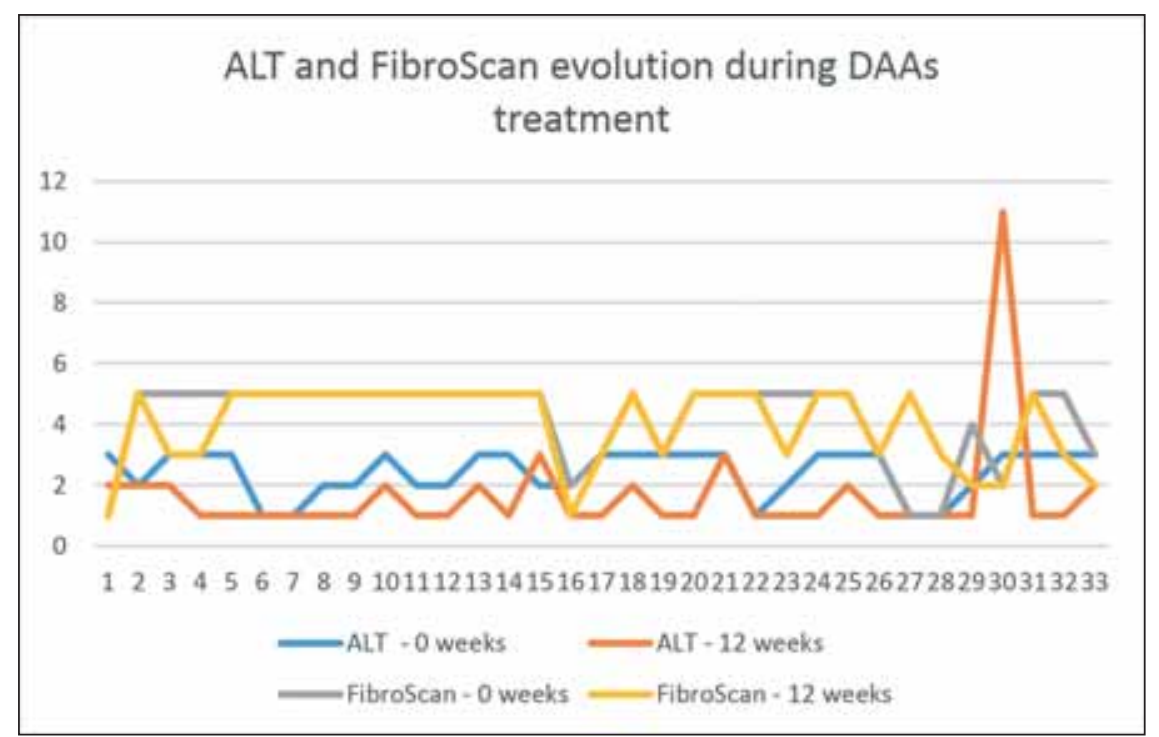

Figure 8. The evolution of liver fibrosis and inflammatory syndrome

Concerning the adverse events during Exviera+Viekirax therapy, we had only one female patient, 66 years old, non-responder to PEG-IFN + RBV therapy, with acute cholecystitis episode. Fortunately, only with medical treatment, this episode was resolved.

All patients had non-detectable viremia at the end of treatment (100\% SVR).

\section{CONCLUSIONS}

1. The limited efficacy of PEG-IFN and Ribavirin therapy, combined with the cost and the adverse events, generated much interest in identifying new antiviral drugs (6).

2. Although Romania does not have available several DAAs, Exviera + Viekirax regimen was shown to be effective in patients treated in the period 02.2016-08.2016, Center of Internal Medicine, Fundeni Clinical Institute.

3. Inflammatory syndrome decreased significantly during treatment with DAAs, so $87.87 \%$ of patients had normal transaminases at the end of therapy.

4. The levels of serum bilirubin became normal in $72,72 \%$ of subjects, at the end of treatment.

5. Liver fibrosis has not recorded any significant changes, but for this we need more followup periods to be able to formulate a conclusion.

6. All patients had undetectable viremia at the end of treatment.

7. In Center of Internal Medicine - Fundeni Clinical Institute, more patients are during the DAAs treatment so after all of them will finish the therapy, more data will be available.

\section{REFERENCES}

1. Joseph S. Doyle, Margaret E. Hellard, Alexandr J. Thompson. The role of viral and host genetics in natural history and treatment of chronic HCV infection. Best Practice \& Research Clinical Gastroenterology 26 (2012) 413-427.

2. Shepard C.W., Finelli L., Alter M.J. Global Epidemiology of hepatitis C virus infection. Lancet Infect Dis 2005(9): 558-67.

3. Perz J.F., Armstrong G.L., Farrington L.A., et al. The contributions of hepatitis $B$ virus and hepatitis $C$ virus infections to cirrhosis and primary liver cancer worldwide. J Hepatol 2006;45(4): 529-38.

4. Poynard T., Bedossa P., Opolon P. Natural History of of liver fibrosis progression in patients with chronic hepatitis C. The OBSVIRC,

METAVIR, CLINIVIR, and DOSVIRC groups. Lancet 1997, 349(9055):825-32

5. Tomas D.I., Astemborski J., Rai R.M. et al. The natural history of hepatitis $C$ virus infection: Host, viral and environmental factors. J Am Med Assoc 2000;284(4):450-6.

6. Berg T., Krauth C., Rossol S., Stahmeyer J. The Eco-Hep Report A macroeconomic overview of viral hepatitis $C$ in Germany. Leberhlife Projekt Gug ( Liver Help Project Ltd.)

7. Raymond T., Chung M.D., Thomas F., Baumert M.D. Curing Chronic Hepatitis C - The Arc of a Medical Triumph. N Engl J Med 370;17. April 24, 2014. 